1964 ; Hanson et al., 1966 ; Sannerstedt, 1966) the relative depression of cardiac output was similar in the two groups in spite of the electrocardiographic differences. The peripheral resistance rises on standing and then falls during exercise. In group II the resistance does show a tendency to be higher than in group I, as might be expected from the higher systolic pressures, but the changes were not significant. The finding that the mean heart rates as well as the mean cardiac outputs show no difference in the two groups of patients indicates that there is also no difference in stroke volume.

Provided there is no change in ventricular volume, the ejection rate reflects the velocity of shortening of the individual myocardial fibres. Patients in group II tend to have bigger hearts on the chest $x$-ray examination than those in group I. This finding suggests an increase in left ventricular volume in group II, though we have shown a poor correlation between heart size on chest $x$-ray examination and direct measurements of left ventricular volume in aortic stenosis (Fleming and Hamer, 1968). The slightly faster ejection rate of group II subjects could be accounted for on this basis, as an identical velocity of contraction in a larger ventricle will result in a faster rate of ejection. The relation of the velocity of fibre contraction to the force generated is a useful way of assessing the contractile state of the myocardium (Sonnenblick, 1962). As the force generated by the myocardium in group II patients is, because of both pressure and volume changes, if anything greater than in group I and the ejection rate is no lower, there is no evidence from our studies of impaired myocardial contractility in the patients with the more severe electrocardiographic changes. The higher systolic blood pressures in our patients in group II suggests that the myocardium has to generate greater force in those with $S-T$ segment and $T$-wave changes. This finding is consistent with the hypothesis that a greater intraventricular systolic pressure leads to a primary change in the S-T segments and $T$ waves by producing localized subendo- cardial changes which may alter the direction of repolarization (Goldberger, 1947) or interfere with the spread of the activation process (Lepeschkin, 1951). However, the S-T and T-wave changes must represent more than a simple mechanical effect, as they do not resolve immediately when the left ventricular pressure is reduced.

Our finding that severe left ventricular hypertrophy on the electrocardiogram is particularly related to systolic blood pressure is in keeping with the suggestion (Ramirez and Garcia Pont, 1965) that cardiac size in hypertension is more closely related to systolic than to diastolic pressure. The evidence suggests, as did our previous work (Hamer et al., 1967), that the systolic pressure is an important determinant of the pathological effect of hypertension on the heart.

\section{REFERENCES}

Ackerman, W., and Katz, L. N. (1933). Amer. Heart 7., 8, 490. Barnes, A. R., and Whitten, M. B. (1929). Amer. Heart f., 5, 14. Cuéllar Padilla, A., Sodi Pallares, D., and Cabrera, E. (1945). Arch. Inst. Cardiol. Méx., 15, 211 .'

Fleming, J., and Hamer, J. (1968). Brit. Heart f. In press.

Goldberger, E. (1947). Unipolar Lead Electrocardiography. Philadelphia. Hamer, J., Fleming, J., and Shinebourne, E. (1967). Lancet, 2, 114. Hanson, J. S., Tabakin, B. S., and Levy, A. M. (1966). Brit. Heart f., 28, 557 .

LaDue, J. S, and Ashman, R. (1946). Amer. Heart 7., 31, 685.

Leishman, A. W. D. (1951). Quart. F. Med., 20, 1.

Leishman, A. W. D. (1951). Quart. F. Med. 20. 1. peschkin, London.

Ramirez, E. A., and Garcia Pont, P. H. (1965). Circulation, 31, 542. Ranges, H. A. (1949) Med. Clin. N. Amer., 33, 611.

Sannerstedt, R. (1966). Acta med. scand., 180, Suppl. No. 458.

Shinebourne, E., Fleming, J., and Hamer, J. (1967). Brit. Heart f., 29, 920.

Simpson, F. O. (1960). Brit. Heart f., 22, 227.

Sokolow, M.

Sonnenblick, E. H. (1962). Amer. F. Physiol., 202, 931.

Sonnenblick, E. H. (1962). Amer. F. Physiol., 202, 931. 414

Wilson, F. N., Rosenbaum, F. F., and Johnston, F. D. (1947). Adranc. intern. Med., 2, 1.

\title{
Intermittent Chemotherapy for Tuberculosis in an Urban Community
}

\author{
GRAHAM POOLE,* M.B., M.R.C.P.; PETER STRADLING, $\dagger$ M.D., F.R.C.P.
}

Brit. med. F., 1969, 1, 82-84 ummary : A regimen designed for effective foolproof
antituberculosis treatment, acceptable on a routine
basis, was applied to all patients newly diagnosed at the
Chest Clinic, Hammersmith Hospital, in 1963, 1964, and
1965. During the first three months of treatment patients
received daily (six days a week) streptomycin 0.75 g. plus
isoniazid 300 mg. plus sodium para-aminosalicylate
(P.A.S.) $12 \mathrm{~g}$. The P.A.S. was usually stopped when
bacterial sensitivity reports made this possible. For a
further 15 months streptomycin 1 g. plus isoniazid 600
mg. was given on three alternate days each week to com-
plete a total of 18 months' treatment.

Of the total of 140 patients (66\% sputum-positive) 112 $(80 \%)$ completed the planned 18 months with intermittent streptomycin plus isoniazid and a further eight completed treatment on alternative regimens (a total of $85 \%$ ). The

\footnotetext{
* Lecturer.

+ Senior Lecturer.

The Chest Clinic, Royal Postgraduate Medical School, Hammersmith Hospital, London W.12.
}

equivalent figures for one year are $88 \%$ and $94 \%$. Excellent clinical and radiological results, together with sputum conversion, were achieved in 138 of the 140 patients $(99 \%)$. Only two patients were lost from surveillance, because of failure to co-operate, before quiescence was obtained.

It is concluded that the total efficiency of supervised intermittent treatment is greater than that of unsupervised daily regimens. Since $100 \%$ arrest of tuberculosis is possible with co-operative patients, less should not be accepted in developed countries.

\section{Introduction}

The management of antituberculosis chemotherapy, even in 흘 developed countries, still poses problems, particularly in relation to drug-taking and the development of bacterial resistance (Simpson, 1956 ; Dixon et al., 1957 ; Fox, 1958, 1962 ; Rigby, 1958 ; Wynn-Williams and Arris, 1958 ; Poole and Stradling, 
1960 ; Preston and Miller, 1964 ; Nicholson, 1967). Since long-term chemotherapy, usually on an outpatient basis, has become the key to relapse-free recovery, the management of all tuberculous patients resolves itself into choosing a regimen that is effective, avoids bacterial resistance, is acceptable to the patient, and has minimal side-effects. These objectives seem most likely to be achieved by regimens employing intermittent therapy for a major part of the course (Tuberculosis Chemotherapy Centre, 1963, 1964 ; Dawson, 1966). Careful consideration must also be given to administrative aspects of the service to ensure that what is planned does in fact take place. This paper does not report a controlled trial; it gives the results obtained with primary treatment during routine management from a London chest clinic where such principles are put into practice-in fact, results attainable in any developed city if a little trouble is taken.

\section{Regimen}

For the first three months of treatment patients were given daily (six days a week) streptomycin $0.75 \mathrm{~g}$. plus isoniazid $300 \mathrm{mg}$. plus sodium para-aminosalicylate (P.A.S.) 12 g. The P.A.S. was usually stopped as soon as bacterial sensitivity reports made this possible. At the end of this period, to complete 18 months in all, the treatment continued on only three alternate days each week with streptomycin $1 \mathrm{~g}$. plus isoniazid $600 \mathrm{mg}$. We agree with Mitchison (1965) that these are the best drugs at present universally available. The total daily quantities of streptomycin and isoniazid were given in single doses, as also was P.A.S. whenever the patient could tolerate it. In the case of both isoniazid (Tuberculosis Chemotherapy Centre, 1960) and P.A.S. (Riska, 1959 ; Lehmann, 1961) there is good evidence that a single large dose is of greater value than smaller divided doses ; certainly oral consumption is easier to supervise. Such supervision was arranged during attendance for injections, whether at the chest clinic, the district nursing centre, other convenient hospital outpatient departments, or the patient's place of employment. A careful register of attendances was kept, so preventing undetected defaulting.

\section{Material}

The records of all tuberculous patients newly diagnosed at the chest clinic, Hammersmith Hospital, during 1963, 1964, and 1965 were analysed. All those whose treatment could be entirely directed by the clinic were started on the regimen and are included in this survey. Only cases presenting as relapsed disease following earlier chemotherapy, and those partly treated elsewhere, were excluded.

There remain 140 patients, with disease of widely varying severity, of whom $66 \%$ had positive sputum or laryngeal swabs. The bacteriologically negative cases were judged to have active tuberculosis by the clinic team and all responded both clinically and radiographically, in the expected way, to chemotherapy. There were 60 females and 80 males; their ages varied from 2 to 75 years. The drug dosages for the few children included were adjusted appropriately.

\section{Results}

\section{Default and Clinical Progress}

Two patients with non-infectious primary lesions were lost sight of during the first three months of treatment: one was a child of 3 years with totally irresponsible parents, the other a juvenile psychotic of 15 years. Four more patients were lost to the survey before the planned chemotherapy could be com- pleted: three had inadequate personalities, and one had overwhelming social problems. These four, however, had done well and the disease was apparently inactive before they disappeared after completing nine months of treatment. The six lost patients represent $4 \%$ of the total analysed. Two further patients disappeared, and are untraced, but not until a year after completing their treatment; they had done well. Finally two patients whose disease had been rendered quiescent after completion of therapy died of other illnesses: one of a coronary occlusion, the other of a carcinoma of the ileum.

It is thus known that 138 of the 140 patients (99\%), including those not completing 18 months of treatment, progressed extremely well, both clinically and radiographically; the bacteriologically positive cases all became negative. There is no reason to suppose that the two patients defaulting in the first three months would not have done equally well had they continued with treatment. Long-term results must await further study, but it is clear that clinical progress was well maintained during the treatment period for all patients, during follow-up periods of two to three years for those diagnosed in 1963, and during one to two years of follow-up for those diagnosed in 1964.

A total of 18 patients failed to complete the 18 months of planned treatment with streptomycin plus isoniazid, but in eight of these, in whom toxic effects were troublesome, it proved possible to carry on with some other drug combination. Thus $120(86 \%)$ patients managed 18 months on some form of chemotherapy, of whom $112(80 \%)$ completed the intermittent streptomycin plus isoniazid. The figures at one year were $94 \%$ and $88 \%$ respectively. It is clear that the great majority of the patients received most of the treatment planned (see Fig.).

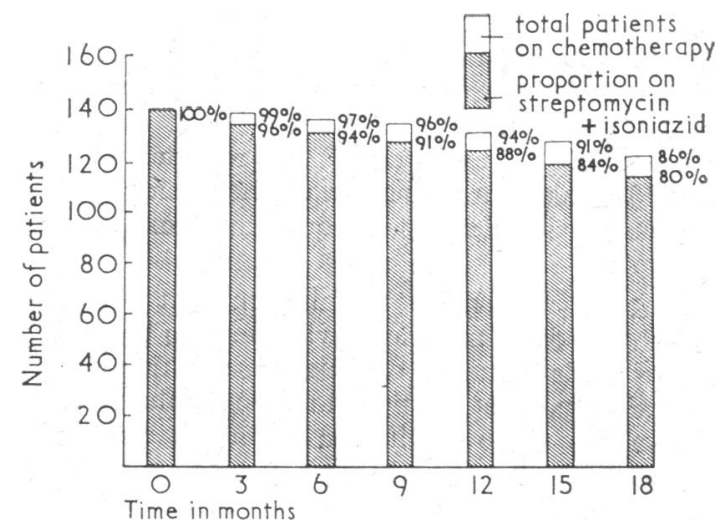

Proportion of 140 patients beginning treatment in 1963-5 who remained on chemotherapy during an 18-month period.

Of the 140 patients $113(81 \%)$ attended, without defaulting, until their treatment terminated ; $27(19 \%)$ missed some treatments (23 missed fewer than 20 treatments, and 4 missed between 20 and 40 ).

\section{Toxicity}

Streptomycin toxicity appeared in a total of 24 instances $(17 \%)$. The ototoxic symptoms were severe enough to necessitate withdrawal of the drug in only nine cases $(6 \%)$. This figure includes six patients suffering toxicity from the $0.75-\mathrm{g}$. dose: five elderly patients early in treatment, and one patient with polycystic kidneys. In 13 other patients milder ototoxic symptoms occurred and, in addition, two developed distressing paraesthesiae. The symptoms were controlled in 13 by reducing the streptomycin dosage from $1 \mathrm{~g}$. to $0.75 \mathrm{~g}$. and in 2 by a further reduction to $0.5 \mathrm{~g}$. (one a very small woman and the other a patient with hydronephrosis). 
In the case of P.A.S., only $46(33 \%)$ could take the drug without trouble, and half the patients complained of minor symptoms but were able to carry on to complete the three months on some preparation of the sodium salt. The remaining $23(16 \%)$ had to abandon it because of intolerable sideeffects. These consisted of nausea, indigestion, flatulence, vomiting, and diarrhoea. One patient also had marked eosinophilia, pyrexia, and a raised level of serum isocitric dehydrogenase-it proved impossible to desensitize this patient.

Only nine cases (6\%) of isoniazid toxicity occurred-all during administration of the $600-\mathrm{mg}$. dose. In eight the symptoms were readily controlled either by simply adding $10 \mathrm{mg}$. of pyridoxine (five cases) or by adding pyridoxine and also reducing the dose of isoniazid to 500 or $400 \mathrm{mg}$. (three cases). The patients' complaints were various ; paraesthesiae, agitation, heaviness in the head, generalized warmth, dizziness, and nausea. In one case the patient, a young student, complained bitterly of loss of concentration which forced abandonment of the drug. The circumstances were such, however, that it was very doubtful if the isoniazid was responsible.

\section{Discussion}

The present paper confirms our preliminary work (Stradling and Poole, 1963 ; Poole and Stradling, 1965) and shows that fully supervised antituberculosis drug therapy, given daily for three months and then on three alternate days each week to a total of 18 months, has been very gratifying. The patient's burden is clearly not too great, particularly when the $0.75 \mathrm{~g}$. daily dose of streptomycin is used (Stradling and Poole, 1963; Johnston et al., 1964): $88 \%$ completed one year on streptomycin plus isoniazid and $80 \%$ the planned 18 months. Early clinical and bacteriological success has been achieved in $99 \%$ and toxic effects of the drugs have been manageable. In a few cases toxicities ( $6 \%$ of those on streptomycin; only one patient on isoniazid) have led to the substitution of other drugs, bringing the total completing treatment to $94 \%$ at one year and to $86 \%$ at 18 months. Menon (1966) also reported excellent early results: $92 \%$ quiescent at one year after using streptomycin plus isoniazid twice weekly without a preliminary period of daily treatment.

It now seems very likely that intermittent drug regimens, after a period of daily treatment, will prove to be entirely competent. But vigilant control of drug consumption, with administrative flexibility, must be applied to protect the patient against his own frailties while at the same time ensuring maximum co-operation and allowing the use of new preparations and knowledge as they become available. Dickinson's (1967) experiments suggest that streptomycin could be expected to be highly effective when used in intermittent regimens, followed in order of effectivity by ethionamide, isoniazid, and ethambutol ; P.A.S. gave variable results. These findings support our choice of streptomycin and isoniazid. The use of streptomycin has another advantage; while it is difficult to devise machinery to make sure that outpatients always consume oral medicines (Zaki et al., 1968), attendance for injections facilitates supervision.
With intermittent regimens the problem of optimum frequency arises. An initial period of daily treatment seems essential for the best results (M.R.C., 1962), but its minimum effective duration is not established. Menon (1966) reported unsatisfactory results using once-weekly treatment; probably this frequency, even after initial daily treatment, would leave no margin of safety. Twice-weekly treatment was substituted for thrice-weekly at this clinic during 1966 and 1967, for the 15 -month period of intermittent treatment. We shall further evaluate the results of this variation, but at present they appear to be equal to those here reported. Further discussion of intermittent treatment is presented in Tubercle (1967).

In view of our experience, reported here, we are increasingly convinced that the total efficiency of fully supervised intermittent treatment is greater than that of even daily regimens if they fail to safeguard against the patients' frailties. The diligent administrative control necessary is well worth the effort. It remains a first principle, particularly important with a communicable disease, to try to cure all patients and to avoid the development of drug resistance. At the same time we should cautiously be determining the minimum treatment necessary to achieve this without subsequent relapse. This goal should result in the desirable by-products of simplicity, economy, and, above all, convenience to the patient. "Successful" is a relative term; but today, when treating tuberculosis, it can mean $100 \%$ arrest of the disease in co-operative patients. It is our duty to strive for this figure whenever the administrative framework makes it possible. If this is not the case, then, in our opinion, subject to available finance, the framework should be altered to make it so. To accept less in a developed country would be indefensible.

\section{REFERENCES}

Dawson, J. J. Y. (1966). Tubercle (Lond.), 47, 241.

Dickinson. J. M. (1967). Brit. med. F., 4, 231

Dixon, W. M., Stradling, P., and Wootton, I. D. P. (1957). Lancet, 2, 871 .

Fox, W. (1958). Tubercle (Lond.), 39, 269

Fox, W. (1958). Tubercle (Lond.), 39, 269. 44, 1, 307. Amsterdam.

Johnston, R. N., Smith, D. H., Ritchic, R. T., and Lockhart, W. (1964). Brit. med. F., 1, 1679.

Lehmann, J. (1961). Wien. med. Wschr., 111, 803.

Medical Research Council (1962). Tubercle (Lond.) 43, 201.

Menon, N. K. (1966). Int. Un. Tuberc. Quart. Rev., No. 17, p. 3.

Mitchison, D. A. (1965). Brit. med. F., 1, 1333.

Nicholson, W. A. (1967). Brit. med. f., 3, 730.

Poole, G., and Stradling, P. (1960). Brit. med. f., 1, 161.

Poole, G., and Stradling, P. (1960). Brit. med. Fubercle (Lond.), 46, 290

Preston, D. F., and Miller, F. L. (1964). Amer. F. med. Sci., 247, 21.

Preston, D. F., and Miller, F. L. (1964). Amer. F.

Riska, N. (1959). Acta tuberc. scand., 37, 104.

Simpson, J. McD. (1956). Tubercle (Lond.) 37, 333.

Stradling, P., and Poole, G. (1963). Tubercle (Lond.), 44, 71.

Tubercle (Lond.), 1967, 48, 58.

Tuberculosis Chemotherapy Centre, Madras (1960). Bull. Wld Hlth Org.,

23, 535.

Tuberculosis Chemotherapy Centre, Madras (1964). Bull. Wld Hith Org., 31, 247.

Wynn-Williams, N., and Arris, M. (1958). Tubercle (Lond.), 39, 138.

Zaki, M. H., Edelstein, S., Josephson, R. A., and Weisberg, S. R. (1968). Amer. Rev. resp. Dis., 97, 136. 